\title{
BMJ Open Qualitative study of the needs of injured children and their families after a child's traumatic injury
}

\author{
Samantha Jones (D) , ,2,3 Sarah Tyson, ${ }^{1,3}$ Naomi Davis, ${ }^{2,3}$ Janelle Yorke ${ }^{1,3}$
}

To cite: Jones S, Tyson S, Davis N, et al. Qualitative study of the needs of injured children and their families after a child's traumatic injury. BMJ Open 2020;10:e036682. doi:10.1136/ bmjopen-2019-036682

- Prepublication history and additional material for this paper is available online. To view these files, please visit the journal online (http://dx.doi.org/10. 1136/bmjopen-2019-036682)

Received 26 December 2019 Revised 09 September 2020 Accepted 15 October 2020

Check for updates

(C) Author(s) (or their employer(s)) 2020. Re-use permitted under CC BY-NC. No commercial re-use. See rights and permissions. Published by BMJ.

${ }^{1}$ Division of Nursing, Midwifery \& Social Work, School of Health Sciences, Faculty of Biology, Medicine and Health, University of Manchester, Manchester, UK ${ }^{2}$ Department of Paediatric Trauma \& Orthopaedics,

Manchester University NHS

Foundation Trust, Royal

Manchester Children's Hospital,

Manchester, UK

${ }^{3}$ Manchester Academic Health

Science Centre Manchester,

Manchester, UK

Correspondence to

Samantha Jones;

samantha.jones-3@manchester. ac.uk

\section{ABSTRACT}

Objective To explore the needs of children and their families after a child's traumatic injury.

Design Semi-structured qualitative interviews with purposeful sampling for different types of injuries and a theoretical thematic analysis.

Participants 32 participants; 13 children living at home after a traumatic injury, their parents/guardians $(n=14)$ and five parents whose injured child did not participate.

Setting Two Children's Major Trauma Centres (hospitals) in England.

Results Interviews were conducted a median 8.5 months (IQR 9.3) postinjury. Injuries affected the limbs, head, chest, abdomen, spine or multiple body parts. Participants highlighted needs throughout their recovery (during and after the hospital stay). Education and training were needed to help children and families understand and manage the injury, and prepare for discharge. Information delivery needed to be timely, clear, consistent and complete, include the injured child, but take into account individuals' capacity to absorb detail. Similarly, throughout recovery, services needed to be timely and easily accessible, with flexible protocols and eligibility criteria to include injured children. Treatment (particularly therapy) needed to be structured, goal directed and of sufficient frequency to return injured children to their full function. A central point of contact is required after hospital discharge for advice, reassurance and to coordinate ongoing care. Positive partnerships with professionals helped injured children and their families maintain a sense of hope and participate in joint decision making about their care. Conclusion Throughout the full trajectory of recovery injured children and their families need family centred, accessible, flexible, coordinated health services, with more effective harmonious, communication between professionals, the child and their family. There is a requirement for support from a single point of contact and a system that monitors the needs of the injured child and their family after hospital discharge.

\section{INTRODUCTION}

Injury is a leading cause of death and disability in children and young people, ${ }^{1}$ which can affect quality of life and result in a significant burden of care over the child's life span. $^{2}$ Centralised major trauma systems have demonstrated improvements in survival from severe injury. ${ }^{3}$ Despite the improvements in

\section{Strengths and limitations of this study}

To improve the generalisability of the results, we used purposeful sampling for maximum variation, rather than a sample of convenience and we believe the participants in this study are broadly representative of children with traumatic injuries and their families.

- To our knowledge, this is the first study to examine needs throughout recovery for a range of different injuries and ages from the perspectives of both the injured children and their parents.

- Different needs may have been identified if the interviews had involved more fathers and/or greater numbers of participants across the different age ranges.

- Joint interview formats may have influenced or limited the scope of the topics discussed by either the child or the parent. However, a positive aspect of this format was that parents were able to provide insightful prompts beyond the scope of the researcher.

- Self-reported needs are subjective and have not been quantified with any objective measurements.

- No data are available relating to the ethnicity of the study participants. Therefore, we do not know if the sample reflects population diversity.

acute care, the rehabilitation which follows is an emerging priority for improvement. ${ }^{4}$ The imperative to strengthen children's trauma rehabilitation reflects the global issue of unmet rehabilitation needs. ${ }^{5}$

It is important to improve children's care beyond the acute hospital admission to enable children to reach their full emotional, social, physical and vocational potential. ${ }^{6}$ However, health and education services are generally aimed at children with development disabilities or long-term conditions rather than those acquired from an injury. ${ }^{7}$ Children with newly acquired injuries are unlikely to have access to standardised pathways of care or long-term therapists who are well versed in their needs. The unique nature of each child's injury, situation and difficulties means that rehabilitation ought to be tailored to their specific 
needs. Thus, an effective starting point for rehabilitation is to understand the needs of the injured child and their family to enable an individualised approach to their care.

Previous research, including our work to review needs following childhood injury, ${ }^{8}$ highlighted a range of needs; particularly support with psychosocial problems for the injured child and their other family members, ${ }^{8-16}$ as well as for physical and practical problems. ${ }^{13} 1718$ Support is required to facilitate the child's transitions from hospital to home, ${ }^{19}$ and return to school. ${ }^{20} 21$ The provision of information has been shown to reduce parents' anxiety ${ }^{19}$ and increase participation in the care of their child. ${ }^{22}$ In trauma-related research, the need for information about the injury and its management are reoccurring themes. ${ }^{9142324}$ However, the current evidence base focuses predominately on the needs of children with traumatic head injuries,, 131625 and mainly considers the needs of parents or family members rather than the injured child, ${ }^{9} 142627$ or the specific needs of adolescents. ${ }^{28}{ }^{29}$ As trauma involves the whole-body system, it is important for clinicians to understand needs for different types of injuries. In addition to head injuries, children suffer from injuries to the limbs/pelvis, spine, abdomen and thorax, which occur in a variety of combinations. ${ }^{30}$ Childhood head injuries often result in cognitive, behavioural and functional impairments, ${ }^{11} 253132$ while other types of injuries (orthopaedic, abdominal and thoracic injuries) cause mainly physical problems, such as pain, loss of mobility and breathing difficulties. Head injuries are often thought of as invisible injuries, ${ }^{9}$ which could also be the case for internal organ injuries, but orthopaedic injuries are often associated with visible physical signs, such as a cast or the use of mobility aids. All types of injuries have the potential to affect psychological health and/or to be life changing. ${ }^{15}$

This study aims to address this gap in the evidence by exploring the needs of injured children and their parents, including children with a wider range of ages and injuries affecting different body parts. This will help to inform the delivery of family-centred services.

\section{METHODS}

\section{Study design and setting}

This was a qualitative interview study conducted at two Children's Major Trauma Centres in England between March 2018 and August 2019.

\section{Participants}

Major trauma coordinators in the participating centres screened admission records to identify potential participants to take part in the study. To be included participants needed to be:

1. Children aged 6-15 years at the time of injury admitted to a specialist Major Trauma Centre with moderate to severe traumatic injury (Injury Severity Score $>8$ ) who were discharged from the Centre within the previous 12 months.
2. Parents or guardians of injured children who fulfilled the criteria.

3. Parents of younger children aged 2-5 years at the time of injury were also included.

The following exclusion criteria were applied:

1. Participants who had been discharged within the previous 2 weeks (as it was felt that they would have insufficient experience of being home to fully contribute).

2. Babies/infants (less than 2 years old).

3. Children with isolated burn injuries (as they were managed by separate care pathway).

4. Non-accidental injuries, or those for whom there were significant safeguarding concerns.

A purposeful approach to sampling was used to account for perspectives from a range of injuries, genders, ages and times since injury.

\section{Data collection}

Potential participants were invited to take part by using age appropriate study information packs which were either posted or provided in person by a trauma coordinator. Consent was obtained from the parents and assent from the children before the interview started. All interviews were conducted by SJ who is a clinical researcher/ major trauma coordinator and has completed training in interviewing children. A flexible interview format was used and participants could choose: who participated (joint child and parent or solely the child or parent), where the interview took place (home, hospital, neutral location) and how the interview was conducted (telephone, face to face). However, for interviews involving children a face-to-face format was recommended.

A semi-structured topic guide was used to explore the child's and when appropriate, parent's or family's needs (see online supplemental appendix 1). Some of the questions in the topic guide are dealt with in companion papers addressing children's and family's experiences and educational needs which are in preparation and will be published in due course. Questions were simplified to suit children of younger ages. Interview questions related to participants' perceptions of the care and support they received throughout recovery (during inpatient care and after hospital discharge), but the semi-structured nature of the interviews allowed participants to explore other topics which they considered relevant. Interviews were digitally recorded and transcribed verbatim.

\section{Analysis}

Anonymised transcriptions were thematically analysed using Excel and NVivo V.11. A theoretical thematic analysis was use to analyse the data, which was considered to be the most suitable method of analysis as a specific research question had already been identified. ${ }^{33}$ When using a theoretical thematic approach, the analysis is driven by the researchers' knowledge and experience in the field. The researcher had insights into the needs of injured children and their families because of her clinical and research experience with this group and topic. ${ }^{8}$ 
The results of the scoping review relating to the needs of injured children and their families were used to produce a preliminary framework of key themes. ${ }^{8}$ First, SJ became familiar with the data by rereading the transcripts. She then coded the data to categorise it within the existing coding framework or determine whether codes pointed towards a new theme. The research team (SJ, ST and JY) met regularly to review the coded data, verify its relevance to main themes and discuss the interpretations, alternative explanations for emergent findings and agree on any new theme headings which were required. Data were coded as interviews were conducted. Data collection ceased once data saturation and sufficient variation in the sample were attained. Data saturation was deemed as the point at which coded data from new interviews only added to existing themes and no new themes were developed. Field notes were maintained for the interviews to contextualise and reflect on the data, such as how forthcoming children were in the interviews.

\section{Patient and public involvement}

The Women and Children's Patient and Public Involvement Team from Manchester Academic Health Science Centre provided feedback on the study documents (patient information sheets, consent and assent forms).

\section{RESULTS}

Twenty-six interviews were conducted involving 32 participants; 13 children and their parents/guardians $(n=14)$ and 5 parents whose injured child did not participate. One child was too young to participate according to the study criteria, one child did not wish to take part, for one child it was logistically too difficult to arrange a face-toface interview and two children were receiving psychological support and they and/or their parents did not feel they could manage the potential psychological impacts of an interview.

Interview duration ranged $11-76 \mathrm{~min}$. The format for the interviews is summarised in table 1 and the characteristics of injured children in table 2. All the interviews conducted in person took place in participants'
Table 2 Characteristics of injured children (13 participants and 5 who did not participate but whose parents were interviewed)

\begin{tabular}{ll}
\hline Characteristics & \\
\hline Gender & Male 11 \\
& Female 7 \\
Age at time of interview & Range 5-16 (median 13.0, IQR \\
(years) & 3.5 ) \\
Injury mechanisms & 4 road traffic accidents \\
& 3 sport \\
& 1 fall $>2$ m \\
& 5 falls $<2$ m \\
& 5 other mechanisms \\
& 1 isolated head injury \\
& 1 isolated spinal injury \\
& 3 isolated abdominal injuries \\
& 1 abdomen and chest injury \\
Type of injury & 6 injuries to limb(s) \\
& 6 multiple injuries \\
& Range 1-12.5 (median 8.5, \\
& IQR 9.3) \\
\hline
\end{tabular}

homes, with the exception of two interviews which were conducted at the hospital (one parent interview and one parent-child dyad interview).

Most participants, particularly the children were unfamiliar with the concept of 'needs' as this is an abstract concept coined by healthcare professionals, thus they seldom talked specifically about their needs. However, needs were implicit in all participants' narratives about how their healthcare was delivered, regardless of whether they were satisfied with their care or whether their needs had been met. Participants described their own unique experiences and although these varied, they often pointed towards the same types of needs. The interviews focused on care after hospital discharge, but the researcher gave participants the flexibility to discuss matters which were

Table 1 Interview structure

\begin{tabular}{|c|c|c|c|}
\hline Interview format & Participants & Method & No of participants \\
\hline 5 parents only & 5 mothers & $\begin{array}{l}3 \text { telephone } \\
2 \text { in person }\end{array}$ & 5 \\
\hline
\end{tabular}
guardian)

\begin{tabular}{llll}
$\begin{array}{l}7 \text { dyads } \\
\text { (child and their parent interviewed separately) }\end{array}$ & $\begin{array}{l}7 \text { children and their parents } \\
(7 \text { mothers })\end{array}$ & All in person 14 \\
\hline $\begin{array}{l}1 \text { triad } \\
\text { (child interviewed separately, mother and father }\end{array}$ & $\begin{array}{l}1 \text { child and their parents } \\
(1 \text { mother and 1 father) }\end{array}$ & All in person 3
\end{tabular}
together) 


\section{Table 3 Education, training and information needs}

\begin{tabular}{|c|c|}
\hline Themes & Quote and participant \\
\hline \multirow[t]{3}{*}{$\begin{array}{l}\text { Education and training } \\
\text { needs }\end{array}$} & $\begin{array}{l}\text { (1a) ... They did say to us that [it] would be....... a miracle if they managed to save his eye. That was } \\
\text { our worst-case scenario. (Parent 11) }\end{array}$ \\
\hline & $\begin{array}{l}\text { (1c) if there would have been any side effects, or things, to look out for, you know?...like I suppose } \\
\text { like you get on any medicine (Parent 26) }\end{array}$ \\
\hline & $\begin{array}{l}\text { (1d) That really did help...... just felt prepared then. It was like 'right, we can do it at the hospital, we } \\
\text { can do it at home.' (Parent 12) }\end{array}$ \\
\hline \multirow[t]{2}{*}{ Information needs } & $\begin{array}{l}\text { (1e) I don't understand why a hospital can't just get in the modern world and email people....... } \\
\text { phone them up and do a referral. Why they have to type and dictate a letter and it takes two weeks for } \\
\text { it to get to the person they need it to get to. (Parent } 8 \text { ) }\end{array}$ \\
\hline & $\begin{array}{l}\text { (1h) It said ... 'fractured skull'. We were like,..., 'it's the first we've heard of it'... So, that was kind of } \\
\text { disappointing really, that we hadn't heard that. (Parent 18) }\end{array}$ \\
\hline \multirow{2}{*}{$\begin{array}{l}\text { Information } \\
\text { needs: effective } \\
\text { communication and } \\
\text { information sharing }\end{array}$} & $\begin{array}{l}\text { (1i) We can just email at any stage if we've got any questions, which is fantastic. Anything I'm worried } \\
\text { about, just email and they'll...respond straightaway. (Parent 9) }\end{array}$ \\
\hline & $\begin{array}{l}\text { (1j) I thought that was really good actually. A lot of the time they speak to [Injured child] rather than to } \\
\text { me? Because he's the injured one and worrying. (Parent 23) }\end{array}$ \\
\hline
\end{tabular}

important to them including hospital care. School-based service needs were identified in the analysis, but have been addressed in a separate paper due to the range and depth of information obtained relating to these needs. This paper is in preparation. Parents and older children were able to give the most information about their needs.

Four overarching themes emerged; education and training needs, information needs, service needs and positive partnerships between children, families and professionals. Education and information needs are interrelated. Education/training needs focus on what children and families need to help them look after the injury, while information needs relate to how advice is delivered.

\section{Education and training needs \\ Education needs}

Both injured children and their parents had to assimilate a large amount of information about the accident and injury(ies). For most this was a completely unfamiliar situation and they recognised that they had a lot to learn. Professionals needed to help by educating them about their injury and how to manage it. Parents highlighted the need to be warned or advised about the prognosis and forewarned about symptoms (such as pain, seizures, hallucinations, difficulty concentrating, fatigue) which sometimes occurred unexpectedly. It was also important to understand the reasons why they occurred (table 3: quote $1 \mathrm{a}, 1 \mathrm{~b}, 1 \mathrm{c})$.

\section{Training needs}

Participants identified that they needed training, particularly in preparation for hospital discharge. This included issues such as how to look after wounds and scars, mobilise, and return to activities and school. They needed opportunities to develop coping strategies and to practice ongoing care and treatments while in hospital to develop competence. This then gave them confidence to execute these tasks at home. For more severely injured children this need went beyond merely practising in the hospital environment. The opportunity to practice at home during weekend leave made the eventual return home more manageable (table 3: quote 1d).

\section{Information needs}

Participants needed timely information to be provided in sufficient detail to understand 'what was going on'. Delays in receiving information predominately related to administration (particularly referrals and transfer of health records), meetings and short notice of operation cancellations. Several found the systems in place outdated (table 3: quote 1e). The desired level of detail varied, but all participants needed information to be clear and consistent. They often explained how helpful they found 
well-executed explanations from professionals (table 3: quote 1f).

Consistency of information was essential, but it was often conflicting. Participants attributed this to the use of medical jargon in written and verbal reports, the number of professionals involved in care and the different approaches between health professionals/ hospitals (table 3: quote 1g). This conflicting information and advice caused 'tension' and 'confusion.' Participants reported that they were sometimes left not knowing what to expect or the best way of managing the injuries. They recommended closer liaison between health professionals.

Related to consistency of information was participants' need for up-to-date information. They needed to be informed clearly and consistently about any changes in diagnosis, prognosis, management plan or expected symptoms throughout all stages of their care. Information was often considered insufficient. Gaps in information delivery were attributed to health professionals not spending enough time with participants, not knowing specific facts or presenting the information which they considered the most important. For example, one family only became aware of the full details of their child's head injury when they reviewed the consent form for a procedure (table 3: quote $1 \mathrm{~h}$ ).

\section{Effective communication and information sharing}

Participants were asked about how information was provided and what they wanted and needed. Irrespective of the format, participants identified that information needed to be available quickly and easily. Most parents considered written information to be useful, particularly copies of clinic and referral letters and other relevant correspondence. This enabled them to monitor progress of care and to play an active role in their child's care. Written information was frequently needed to share information with other health professionals and external agencies (such as schools) who often required 'a written letter from a doctor.' Several found it difficult to absorb written information (such as leaflets and booklets) given their emotional state, although participants acknowledged these were valuable 'to refer back to'. However, many parents preferred to liaise directly with healthcare professionals in person or via texts, phone-calls and emails as their primary source of communication and information (table 3: quote 1i). Similarly, injured children preferred to ask their parents questions rather than professionals. However, open conversations with professionals which included and were directed towards the injured child were valued (table 3: quote $1 \mathrm{j}$ ). The use of visual aids, such as X-rays and scans also helped participants understand the injury, particularly when there were no visible physical signs. One child used his abdominal scan to help his peers understand the severity of his injury.

Dissatisfaction with information and communication arose when healthcare professionals repeatedly asked the same questions, did not share information and/or did not advise participants of the outcomes of investigations, test results or changes to care plans.

\section{Service needs}

Participants were clear about what they needed from services throughout their recovery. Whether inpatient or community based, they needed services to be accessible, timely, sufficient, structured and coordinated. Although many participants expressed positive experiences and satisfaction, this was not universal. The types of difficulties outlined were not limited to one type of service: unmet needs for accessible services were described for most types of community-based services.

\section{Accessible and timely services}

After hospital discharge, services needed to be provided locally or at the participants' homes, often 'out of hours' or with 'open appointments' to enable participants to obtain care or assessments when needed (table 4: quote 2a). However, many factors made services difficult to access after hospital discharge. Participants described lengthy or difficult journeys to their healthcare provider and strict eligibility criteria which excluded children (table 4 : quote 2b). Additionally, rigid protocols prevented access to services, such as school transport and equipment. For example, one injured child lived in two homes as their parents were separated, but services could not accommodate this commonplace living arrangement and would only supply one set of equipment.

In order to be accessible, some services needed to be made available to family members as well as the injured child. Post-traumatic stress type symptoms and/or mental health issues were often experienced by an injured child and their family members, including parents, grandparents and siblings (participants' experiences will be reported in detail in a pending publication). Although the hospital offered psychological support to the whole family, this holistic approach was more difficult to access in the community after hospital discharge (table 4: quote 2c). However, several participants did not take up psychological support during inpatient stay, as difficulties often only became apparent after discharge when participants tried to return to 'normal life'.

The timing of services was very important; participants often experienced long delays for services to start (particularly community therapy) and cancelled operations. Such delays were difficult for families to cope with (table 4: quote 2d). A couple of participants proposed that appointments could be quicker if telephone consultations were available after discharge, or if primary and secondary care services worked more closely together to prioritise injured children more appropriately (child 21 and parent 22).

\section{Dose and structure of treatment}

Whether during inpatient or community-based care, participants needed services to provide sufficient treatment throughout the continuum of recovery. In the 
Table 4 Service needs

Themes Quote and participant: Service needs

Service needs: Accessible and timely services

(2a) We had an open appointment arrangement with the physio, where we could ring up if there was a problem. (Parent 6)

(2b) They [district nurses]... told me that they don't deal with anybody under the age of eighteen. (Parent 8)

(2c) I think we were offered everything we... could have been. I think getting counselling for me mum (child's grandparent) was a bit harder... [referring to experience after hospital] (Parent 11)

(2d) We were thrown into two weeks of, is he having brain surgery, is he not? And it happened, you know, twice, two cancellations. And that is such a huge thing for your heart to cope with. (Parent 18)

Service needs: Dose and structure of treatment

(2e) We could just see that it [physiotherapy] wasn't gonna be what [injured child] needed. She needed more...... she wasn't even gonna start for at least a couple of weeks (Parent 9).

(2f) That really helped. We set some [goals] in hospital, didn't we? Something to do in the future like........., what do you want to do for your birthday? So I was like, I'd always wanted to go, like, Harry Potter World or something. (Child 21).

Service needs: Coordination of care

(2g) I don't think I could have coped, if I'd had to ring up all them people and sort all her (injured child's) care package out, I couldn't have coped. (Parent 2)

(2h) well we've got his appointment through. As I say, we were expecting it. They said it would be within six weeks, but it's actually 13 ...it'll be 13 weeks since the accident. (Parent 26)

(2i) When I rang the nurse though, they were really reassuring, and they sort of said 'I don't think it's anything too much to worry about, but mention it to the neurosurgeons'. So, it did allay my fears a bit. (Parent 19)

(2j) he just reassured me a lot and answered a lot of questions that I had about going ....back to school and sorting things out (Child 21) hospital, a lack of nursing staff was highlighted as a key issue. However, there was a notable discrepancy between satisfaction with mental health and therapy services in the hospital and community setting, with such services generally regarded as comprehensive in the hospital, but lacking in the community. After discharge from hospital, participants described a lack of children's mental health services or professionals who deliver specific psychotherapy treatments for children. Similarly, in contrast to the hospital, community-based therapy was often regarded as insufficient (table 4: quote 2e). Another issue was that treatment in the community (often physiotherapy or occupational therapy) needed to have a greater scope of ambition for the injured child's recovery. Rehabilitation goals, whether set with therapists or autonomously were considered essential to gauge improvement, inspire motivation and provide a focus for the future (table 4: quote 2f). Several participants reported that community therapy finished before the injured child had reached their goals to return to physical education, competitive sport or other activities (ie, they had not reached their rehabilitation potential). In order to deal with these unmet rehabilitation needs, participants devised their own exercise and rehabilitation regimes; requested physiotherapy reviews or funded therapy privately. Participants also needed rehabilitation to be clearly structured because the injury(ies) disrupted their usual routines.

\section{Coordination of care and ongoing support}

Care and rehabilitation of children with traumatic injuries often involved input from multiple professionals and services over an extended period to manage complex, sometimes sensitive problems. Participants very clearly articulated the need for this complex, multiagency, multifaceted, often long-term care to be coordinated by a healthcare professional. They highlighted the need for help to coordinate timely provision of appropriate equipment, appointments, care packages and return to education (whether this be school or home schooling) and other activities (table 4: quote $2 \mathrm{~g}$ ).

Coordinating ongoing care after discharge, such as clinic appointments and referrals were a particular issue for most participants, regardless of the severity or complexity of the injury or the number of specialist services involved. They valued help to ensure referrals and appointments were made, attempts to streamline appointments to minimise the number of trips and disruption to schooling and employment, prompt notification of appointments, timely reminders and help to rearrange appointments if necessary. When this coordination was not available, participants described unsatisfactory experiences (table 4 : quote $2 \mathrm{~h}$ ).

Most participants acknowledged that they needed a named contact to be involved throughout their hospital stay, through discharge and for ongoing care. 
This professional needed to provide the coordination described above, plus ongoing monitoring of recovery and needs, reassurance, emotional support and continued advice especially about new symptoms. (table 4: quotes $2 \mathrm{i}$ and $2 \mathrm{j}$ ). Where available this named contact was often a trauma coordinator, but participants also found their general practitioner a helpful point of reference and a means of accessing other services. Part of the coordinator's role also needed to 'signpost' children (and their families) to access appropriate ongoing care. Participants reported how problems and symptoms, particularly posttraumatic distress and mental health problems often only became apparent after hospital discharge. To address such new problems, participants needed to know what sources of help were available and how to access them. They described how they needed 'to be put in touch with the right people'. This signposting role extended beyond healthcare services.

There was a particular need to coordinate multiagency care (usually for the more severely injured children) as participants did not have the knowledge, skills or experience to negotiate the highly complex and variable systems, particularly when community or education services were involved. Many met and unmet needs were highlighted regarding return to education (whether at school or at home) after a traumatic injury and these are addressed in a separate manuscript, which is in preparation.

\section{Partnerships between patients and professionals}

Participants explained how they needed positive, supportive, trusting partnerships with the professionals involved in their care. A positive outlook from professionals helped to boost morale and gave a sense of hope and helped injured children and their families feel emotionally supported (table 5: quote 3a). This also related to the need to be able to trust the skills, competence and reliability of the professionals and organisations involved in the injured child's care, which gave them confidence and reassurance (table 5 : quotes $3 \mathrm{~b}$ and 3c). This trust was also needed to persuade the injured children to adhere to aspects of treatment which they disliked and enabled professionals and participants to work effectively together (table 5: quote $3 \mathrm{~d}$ ). Several children disliked certain aspects of their treatment (eg, wearing an eye patch or orthotic devices) and were reluctant to adhere to them. To minimise this problem, children and their families needed to 'feel heard', be involved in discussions and decisions about their care, to jointly solve problems by exploring alternative treatment options and finding mutually agreeable solutions or compromises (where possible) (table 5: quote 3e). However, not all relationships between services and participants were positive. There were several reports of perceived problems with care. Examples included the incorrect application of orthotics, medication error, issues with adherence to major trauma pathways, referrals which were not made, delayed appointments and equipment. In these cases, participants felt they had not been listened to by health professionals, nor involved in discussions/decisions about their care. Consequently, they could not rely on some aspects of service provision (table 5: quote 3f).

\section{DISCUSSION}

The results of this study showed that injured children and their families' needs focus on education and training to help understand the injury and how to manage it, effective communication, access to sufficient services, support to coordinate care and positive partnerships with professionals.

Participants' unmet need for clear, consistent and complete information across the full recovery continuum echoes findings from previous studies ${ }^{9} 1323$ and is attributed to the range of professionals often involved in trauma care. ${ }^{23}$ However, participants' needs and preferences varied, so consideration should be given to individualising information and ensuring it is available in a range of different formats, as well as ensuring the injured child and other family members are included in honest

Table 5 Partnerships between patients and professionals

Themes Quote and participant

Partnerships between patients and professionals (3a) They [hospital staff] kept us positive and...yeah, didn't make us feel that, God, this was, you know, absolutely disastrous, but she was gonna get better. (Parent 9)

(3b) I think the fact it was a children's hospital and they knew exactly what they were doing... You feel confident. (Parent 26)

(3c) you know, the people who do these types of operations, they're good at their job (Child 17)

(3d) Originally I couldn't even get (injured child) there (Psychology Department). But the therapist from CAMHS built up such a good relationship. (Parent 12)

(3e) we just discussed it as a whole family and (trauma co-ordinator)...everything that was worrying [Injured Child]... And then she just literally said 'right. I can fix that, that, that, that and that, but I can't do this... but I know somebody who might be able to, so let me look into it, leave it with me.' (Parent 21)

(3f) They [the council] were supposed to provide some equipment for the bath. And it never materialised. They came out, they brought the wrong bath board. And then they said they'd come out again. But they didn't. (Parent 12) 
and open discussions. Additionally, clearer information to manage expectations may be required when details are unknown or subject to change, ${ }^{9}$ particularly care plans. Although written information was often useful, this needed to be conveyed quickly (eg, by email or text) and act as a supplement to verbal communication. Electronic patient held records or portals have been shown to enhance information and communication exchange, ${ }^{34} 35$ and may help to fulfil children's and family's needs for more immediate, accessible and consistent information.

Access to services was a frequent unmet need, which was most pronounced in the community setting. It is unsurprising that most participants described a "post code lottery' when it came to rehabilitation in the community setting. All the participants included in this study had been managed in specialist children's Major Trauma Centres. The resources, standards and clinical governance processes present in these centres only cover hospital-based care ${ }^{4}$ and do not extend to the community setting, where there are few services specifically for injured children. Similarly, disparities in access to postdischarge rehabilitation for childhood traumatic injury have been reported in the USA. ${ }^{6}$ Further research is required to better understand how injured children's communitybased rehabilitation can be provided efficiently and effectively.

Inadequate service provision has been reported previously, ${ }^{791636}$ particularly for services relating to cognitive or mental health difficulties. ${ }^{12} 163637$ The current study reinforces this by highlighting that although psychological support during the inpatient stay was comprehensive, it was lacking after discharge, which is when difficulties often emerged. Psychological support services needed to extend throughout the full recovery trajectory and cater for the needs of the whole family unit. To achieve this, the capacity of children's community mental health services needs to expand by training more professionals, ${ }^{38}$ and educating both parents ${ }^{39}$ and professionals ${ }^{10}$ about how to detect signs of post-traumatic stress, particularly as symptoms can present late in recovery. ${ }^{15}{ }^{40}$ In contrast to previous research, our participants placed more importance on the need for physical and practical support. This may reflect the variety of injuries included in our sample, rather than being limited to head injuries.

There is a clear need to develop comprehensive, streamlined rehabilitation services for children with traumatic injuries, whose needs may be temporary or change over time. Expansion of the Major Trauma Networks to include all facets of rehabilitation for all ages could provide this support, but this would require sustained funding and training. Like previous studies, we found an overwhelming need for a single point of contact during and after hospital discharge ${ }^{98364142}$ to help patients access professional support and to coordinate the multiple professions, specialties, agencies and organisations involved in their care. Coordinators could work in conjunction with rehabilitation medicine consultants, ${ }^{43}$ who would lead clinical decision making. This approach may achieve more streamlined rehabilitation and consistent communication. Some major trauma services provide a specialist coordinator, but this is often limited to hospital-based care. ${ }^{36}$ However, support may be required over the longterm as ongoing problems are highly prevalent for several years after severe injury, ${ }^{42}{ }^{44}$ but may not become apparent until after the child has been discharged from hospital and attempts to return to their normal life. ${ }^{12}{ }^{16}$ Ongoing support may contribute to trusting, positive partnerships that participants emphatically needed for more familycentred care and to enable joint decision making. ${ }^{45}$ In this study and previous research, an important role of a known contact is to provide reassurance and maintain a sense of hope. ${ }^{13-15} 193946$ An important aspect of trauma care is to support the emotional recovery ${ }^{46}$ of the child and their parents. ${ }^{39}$

A system is required that continues to screen for (and then treat and monitor) problems after hospital discharge. This may be most pragmatically addressed by a comprehensive needs assessment tool which can be completed by the child/family at regular intervals throughout the full recovery. Work is underway to develop such a tool that is suitable for all ages of children, types of injury and stages of care.

\section{Strengths and limitations}

A common criticism of qualitative research is the limited generalisability of the results. ${ }^{47}$ To address this, we used purposeful sampling for maximum variation, rather than a sample of convenience and we believe the participants in this study are broadly representative of children with a range of traumatic injuries. ${ }^{30}$ To our knowledge, this is a first study to examine needs throughout recovery for a broad range of injuries and ages from the perspectives of both the injured children and their parents. However, the purposeful approach to sampling did not encompass attaining equal numbers of mothers and fathers. The majority of mothers who took part was an unexpected finding, which may have influenced the range of needs and experiences reported. Previous qualitative studies have shown a difference in themes identified for males and females. ${ }^{48}$

Due to involvement of children and sensitive nature of the interview topic (childhood injury), it was important to give participants the opportunity to take part in the interviews in the way that they felt most comfortable. We acknowledge that joint interview formats may have influenced or limited the scope of the topics discussed by either the child or the parent. ${ }^{49}$ One positive aspect of joint interviews was that parents were able to provide insightful prompts, beyond the scope of the researcher.

Age-specific needs have previously been identified for adolescents. ${ }^{28}$ Our initial intention was to explore agespecific needs, but the data analysis showed that the identified needs were generic across the ages investigated. More age-related needs may have been identified if there were greater numbers of participants across the different 
age ranges and interview probes placed more emphasis on issues relevant to age.

We acknowledge that self-reported needs are subjective and have not been quantified with any objective measurements. Self-reported, subjective data can be influenced by different forms of bias, ${ }^{50}{ }^{51}$ including social desirability bias. ${ }^{51}$ For example, social desirability bias may have occurred because participants wanted to appear to be coping and thus may have under reported their level of need. Finally, we do have data about the ethnicity of the study participants. Therefore, we do not know if the sample reflects population diversity.

\section{CONCLUSION}

This research has helped to identify unmet healthcare needs of a new target population. Children with a range of injuries and their families need family centred, accessible, flexible coordinated health services throughout the full trajectory of recovery, with more effective harmonious communication between professionals, the child and their family. Trauma rehabilitation should be provided as a continuum of care, part of which should involve the ongoing monitoring of the injured child's and family's needs. Services between hospital and community settings need to be more seamless and equitable. This may be achieved by attaining evidence such as that presented here, about needs through the full trajectory of recovery, which can then be used to inform policy and commissioning.

Acknowledgements I would like to thank the trauma/rehabilitation co-ordinators at the participating Major Trauma Centres, and all of the children and family members who participated in the study. I would also like to thank Mary Ingram for her continued support with reference management.

Contributors All authors (SJ, ST, ND and JY) contributed to the conception and design of the work, monitoring progress, critical appraisal and approval of the final version of the manuscript. SJ is the guarantor of the study and led the design of the work, data collection, data analysis, interpretation of the data and produced the manuscript drafts. ST and JY contributed to the design of the work, data analysis and interpretation of the data. ST contributed to drafting the manuscripts. ND contributed to the interpretation of the data.

Funding SJ is funded by a National Institute for Health Research (NIHR), (ICA Programme Clinical Doctoral Research Fellowship (Grant reference ICACDRF-2016-02-021)) for this research project. This publication presents independent research funded by the National Institute for Health Research (NIHR).

Disclaimer The views expressed are those of the authors and not necessarily those of the NHS, the NIHR or the Department of Health and Social Care.

Competing interests None declared.

Patient consent for publication Not required.

Ethics approval The study was approved by the National Health Service, North West - Greater Manchester South Research Ethics Committee (REC reference 17/ NW/0615) and the Health Research Authority.

Provenance and peer review Not commissioned; externally peer reviewed.

Data availability statement All data relevant to the study are included in the article or uploaded as online supplemental information.

Supplemental material This content has been supplied by the author(s). It has not been vetted by BMJ Publishing Group Limited (BMJ) and may not have been peer-reviewed. Any opinions or recommendations discussed are solely those of the author(s) and are not endorsed by BMJ. BMJ disclaims all liability and responsibility arising from any reliance placed on the content. Where the content includes any translated material, BMJ does not warrant the accuracy and reliability of the translations (including but not limited to local regulations, clinical guidelines, terminology, drug names and drug dosages), and is not responsible for any error and/or omissions arising from translation and adaptation or otherwise.

Open access This is an open access article distributed in accordance with the Creative Commons Attribution Non Commercial (CC BY-NC 4.0) license, which permits others to distribute, remix, adapt, build upon this work non-commercially, and license their derivative works on different terms, provided the original work is properly cited, appropriate credit is given, any changes made indicated, and the use is non-commercial. See: http://creativecommons.org/licenses/by-nc/4.0/.

Author note All authors (SJ, ST, ND, JY) contributed to the conception and design of the work, monitoring progress, critical appraisal and approval of the final version of the manuscript. SJ is the guarantor of the study and led the design of the work, data collection, data analysis, interpretation of the data and produced the manuscript drafts. ST and JY contributed to the design of the work, data analysis and interpretation of the data. ST contributed to drafting the manuscripts. ND contributed to the interpretation of the data.

ORCID iD

Samantha Jones http://orcid.org/0000-0001-6393-5274

\section{REFERENCES}

1 Peden M, Oyegbite K, Ozanne-Smith J, et al. World report on child injury prevention. Geneva: World Health Organisation, 2008.

2 Zonfrillo MR, Durbin DR, Winston FK, et al. Physical disability after injury-related inpatient rehabilitation in children. Pediatrics 2013;131:e206-13.

3 Moran CG, Lecky F, Bouamra O, et al. Changing the system - major trauma patients and their outcomes in the NHS (England) 2008-17. EClinicalMedicine 2018;2-3:13-21.

4 Dixon P. The updated trauma system in England - its development and use. Orthop Trauma 2014;28:159-66.

5 Gimigliano F, Negrini S. The World Health Organization "rehabilitation 2030: a call for action". Eur J Phys Rehabil Med 2017;53:155-68.

6 Shah AA, Zuberi M, Cornwell E, et al. Gaps in access to comprehensive rehabilitation following traumatic injuries in children: a nationwide examination. J Pediatr Surg 2019;54:2369-74.

7 Hayes L, Shaw S, Pearce MS, et al. Requirements for and current provision of rehabilitation services for children after severe acquired brain injury in the UK: a population-based study. Arch Dis Child 2017;102:813-20.

8 Jones S, Davis N, Tyson SF. A scoping review of the needs of children and other family members after a child's traumatic injury. Clin Rehabil 2018;32:501-11.

9 Kirk S, Fallon D, Fraser C, et al. Supporting parents following childhood traumatic brain injury: a qualitative study to examine information and emotional support needs across key care transitions. Child Care Health Dev 2015;41:303-13.

10 Sabin JA, Zatzick DF, Jurkovich G, et al. Primary care utilization and detection of emotional distress after adolescent traumatic injury: identifying an unmet need. Pediatrics 2006;117:130-8.

11 Karver CL, Kurowski B, Semple EA, et al. Utilization of behavioral therapy services long-term after traumatic brain injury in young children. Arch Phys Med Rehabil 2014;95:1556-63.

12 Slomine BS, McCarthy ML, Ding R, et al. Health care utilization and needs after pediatric traumatic brain injury. Pediatrics 2006;117:e663-74.

13 Minney MJ, Roberts RM, Mathias JL, et al. Service and support needs following pediatric brain injury: perspectives of children with mild traumatic brain injury and their parents. Brain Inj 2019;33:168-82.

14 Falk A-C, von Wendt L, Klang B. Informational needs in families after their child's mild head injury. Patient Educ Couns 2008;70:251-5.

15 Wiseman T, Foster K, Curtis K. The experience of emotional wellbeing for patients with physical injury: a qualitative follow-up study. Injury 2016;47:1983-9.

16 Fuentes MM, Wang J, Haarbauer-Krupa J, et al. Unmet rehabilitation needs after hospitalization for traumatic brain injury. Pediatrics 2018;141:e20172859.

17 Aitken ME, Jaffe KM, DiScala C, et al. Functional outcome in children with multiple trauma without significant head injury. Arch Phys Med Rehabil 1999;80:889-95.

18 Gabbe BJ, Simpson PM, Sutherland AM, et al. Functional and health-related quality of life outcomes after pediatric trauma. $J$ Trauma 2011;70:1532-8. 
19 Smith L, Daughtrey $\mathrm{H}$. Weaving the seamless web of care: an analysis of parents' perceptions of their needs following discharge of their child from hospital. J Adv Nurs 2000;31:812-20.

20 Todis B, McCart M, Glang A. Hospital to school transition following traumatic brain injury: a qualitative longitudinal study. NeuroRehabilitation 2018;42:269-76.

21 Glang A, Todis B, Thomas CW, et al. Return to school following childhood TBI: who gets services? NeuroRehabilitation 2008;23:477-86.

22 Power N, Franck L. Parent participation in the care of hospitalized children: a systematic review. J Adv Nurs 2008;62:622-41.

23 Braaf S, Ameratunga S, Nunn A, et al. Patient-identified information and communication needs in the context of major trauma. BMC Health Serv Res 2018;18:163.

24 Sleney J, Christie N, Earthy S, et al. Improving recovery-learning from patients' experiences after injury: a qualitative study. Injury 2014;45:312-9.

25 Narad ME, Moscato E, Yeates KO, et al. Behavioral health service utilization and unmet need after traumatic brain injury in childhood. $J$ Dev Behav Pediatr 2019;40:451-7.

26 Foster K, Young A, Mitchell R, et al. Experiences and needs of parents of critically injured children during the acute hospital phase: a qualitative investigation. Injury 2017;48:114-20.

27 Bugel MJ. Experiences of school-age siblings of children with a traumatic injury: changes, constants, and needs. Pediatr Nurs 2014;40:179-86.

28 Gagnon I, Swaine B, Champagne F, et al. Perspectives of adolescents and their parents regarding service needs following a mild traumatic brain injury. Brain Inj 2008;22:161-73.

29 Swaine BR, Gagnon I, Champagne F, et al. Identifying the specific needs of adolescents after a mild traumatic brain injury: a service provider perspective. Brain Inj 2008;22:581-8.

30 Jones S, Tyson S, Young M, et al. Patterns of moderate and severe injury in children after the introduction of major trauma networks. Arch Dis Child 2019;104:366-71.

31 Rivara FP, Koepsell TD, Wang J, et al. Disability 3, 12, and 24 months after traumatic brain injury among children and adolescents. Pediatrics 2011;128:e1129-38.

32 Wade SL, Zhang N, Yeates KO, et al. Social environmental moderators of long-term functional outcomes of early childhood brain injury. JAMA Pediatr 2016;170:343-9.

33 Braun V, Clarke V. Using thematic analysis in psychology. Qual Res Psychol 2006;3:77-101.

34 Powell KR. Patient-Perceived facilitators of and barriers to electronic portal use. CIN: Computers, Informatics, Nursing 2017;35:565-73.

35 Roehrs A, da Costa CA, Righi RdaR, Da Rosa Righi R, et al. Personal health records: a systematic literature review. J Med Internet Res 2017;19:e13.
36 Curtis K, Foster K, Mitchell R, et al. How is care provided for patients with paediatric trauma and their families in Australia? A mixedmethod study. J Paediatr Child Health 2016;52:832-6.

37 Huebner ARS, Cassedy A, Brown TM, et al. Use of mental health services by adolescents after traumatic brain injury: a secondary analysis of a randomized controlled trial. Pm $R$ 2018;10:462-71.

38 Neufeld SAS, Jones PB, Goodyer IM. Child and adolescent menta health services: longitudinal data sheds light on current policy for psychological interventions in the community. J Public Ment Health 2017;16:96-9.

39 Williamson V, Creswell C, Butler I, et al. Parental responses to child experiences of trauma following presentation at emergency departments: a qualitative study. BMJ Open 2016;6:e012944.

40 Skogstad L, Tøien K, Hem E, et al. Psychological distress after physical injury: a one-year follow-up study of conscious hospitalised patients. Injury 2014;45:289-98.

41 Foster K, Curtis K, Mitchell R, et al. The experiences, unmet needs and outcomes of parents of severely injured children: a longitudinal mixed methods study protocol. BMC Pediatr 2016;16:152.

42 Gabbe BJ, Simpson PM, Cameron PA, et al. Long-Term health status and trajectories of seriously injured patients: a population-based longitudinal study. PLoS Med 2017;14:7.

43 NCASRI Project team, Turner-Stokes L. Specialist rehabilitation following major injury (NCASRI) final audit report v.17.0. London: National Clinical Audit of Specialist Rehabilitation following major Injury (NCASRI), 2019.

44 Janssens L, Gorter JW, Ketelaar M, et al. Long-term health condition in major pediatric trauma: a pilot study. J Pediatr Surg 2009;44:1591-600

45 Wolf A, Moore L, Lydahl D, et al. The realities of partnership in person-centred care: a qualitative interview study with patients and professionals. BMJ Open 2017;7:e016491.

46 Tutton E, Seers K, Langstaff D. Hope in orthopaedic trauma: a qualitative study. Int J Nurs Stud 2012;49:872-9.

47 Greenhalgh T, Taylor R. How to read a paper: papers that go beyond numbers (qualitative research). BMJ 1997;315:740-3.

48 Ussher JM, Sandoval M, Perz J, et al. The gendered construction and experience of difficulties and rewards in cancer care. Qual Health Res 2013;23:900-15

49 Gardner H, Randall D. The effects of the presence or absence of parents on interviews with children. Nurse Res 2012;19:6-10.

50 Rosenman R, Tennekoon V, Hill LG. Measuring bias in self-reported data. Int J Behav Healthc Res 2011;2:320.

51 Althubaiti A. Information bias in health research: definition, pitfalls, and adjustment methods. J Multidiscip Healthc 2016;9:211-7. 